\title{
Twenty four hour continuous non-invasive finger blood pressure monitoring: a novel approach to the evaluation of treatment in patients with autonomic failure
}

\author{
S Omboni, A A J Smit, W Wieling
}

\begin{abstract}
Occasional sphygmomanometric readings are not an effective way of evaluating the effect of treatment in patients with hypoadrenergic orthostatic hypotension. A novel non-invasive portable device (Portapres) was used to monitor 24 hour continuous finger blood pressure before and during chronic volume expansion in a 66 year old woman with severe orthostatic hypotension. In both conditions pressures while she was standing were lowest in the morning. Her tolerance to standing and walking increased during the day and, as a consequence of a higher upright mean blood pressure, was improved after treatment. Mean blood pressure during sleep was increased after treatment.

Continuous 24 hour non-invasive finger blood pressure monitoring is a promising technique for the evaluation of the effect of treatment in patients with autonomic failure. It provides information about situations in daily life that cannot be obtained by laboratory tests or conventional sphygmomanometric measurements.
\end{abstract}

(Br Heart f 1995;73:290-292)

Academic Medical Centre, University of Amsterdam, Department of Internal Medicine, The Netherlands $S$ Omboni

A A J Smi

W Wieling

University of Milan, Department of

Internal Medicine,

Italy

S Omboni

Correspondence to:

Dr W Wieling, Department of Internal Medicine,

Academic Medical Center,

University of Amsterdam

PO Box 22700, $1100 \mathrm{DE}$

Amsterdam

The Netherlands.

Accepted for publication

20 September 1994
Keywords: autonomic failure; continuous finger blood pressure monitoring

Ordinary daily activities greatly influence blood pressure in patients with orthostatic hypotension caused by autonomic failure. ${ }^{12}$ Therefore, evaluation of the effect of treatment is difficult because features such as supine hypertension during night sleep or the effect of mild exercise on blood pressure cannot be detected by conventional blood pressure measurements. We report on the results obtained by a novel approach based on continuous, non-invasive, 24 hour finger blood pressure monitoring in a patient with severe hypoadrenergic orthostatic hypotension, before and during treatment with fludrocortisone.
Case report

A 66 year old woman with a 3 year history of symptomatic orthostatic hypotension was referred to our hospital. On admission sphygmomanometric systolic and diastolic blood pressure in the morning was $168 / 94 \mathrm{~mm} \mathrm{Hg}$ supine and $86 / 55 \mathrm{~mm} \mathrm{Hg}$ after 1-2 min standing. Physical examination and routine blood chemistry were normal. Supine noradrenaline was low $(69 \mathrm{ng} / \mathrm{l})$, with an abnormally small increase upon standing (122 $\mathrm{ng} / \mathrm{l}) .^{3} \mathrm{~A}$ diagnosis of pure autonomic failure was established.

Blood pressure was measured over the 24 hours by the Portapres device, a portable recorder to measure beat-to-beat finger blood pressure non-invasively in ambulatory conditions. ${ }^{45}$ With a trained operator, it is as easy to obtain good ambulatory recordings with the Portapres as with common noninvasive intermittent monitors (for example, Spacelabs). In addition, Portapres does not cause any discomfort to the patient, does not appreciately disturb sleeping or interfere with daily activities, and can be repeated as needed in the same subject. In a recent paper it was shown that the blood pressure values provided continuously throughout the 24 hours by the Portapres are close to those simultaneously obtained by beat-to-beat ambulatory intra-arterial recordings. ${ }^{4}$

In our patient a 24 hour recording was performed before and after 7 days of treatment with fludrocortisone $0.1 \mathrm{mg}$ once a day, combined with $12^{\circ}$ head-up tilt sleep, and a 150 mmol sodium diet. ${ }^{6}$ During both recordings, started at 1200, the patient engaged in the same activities and performed a 15 min walk in the afternoon (1600) and the next morning (1000). Effects of standing were assessed before she went to bed (2230) and immediately after waking up (0630). Each blood pressure recording was stored on a magnetic tape cassette and further analysed by a computer to obtain beat-to-beat systolic, diastolic, mean blood pressure, and pulse pressure values. ${ }^{4}$

Mean $24 \mathrm{~h}$ diastolic blood pressure was similar before $(63 \mathrm{~mm} \mathrm{Hg})$ and during treatment $(64 \mathrm{~mm} \mathrm{Hg})$. Conversely, $24 \mathrm{~h}$ systolic 

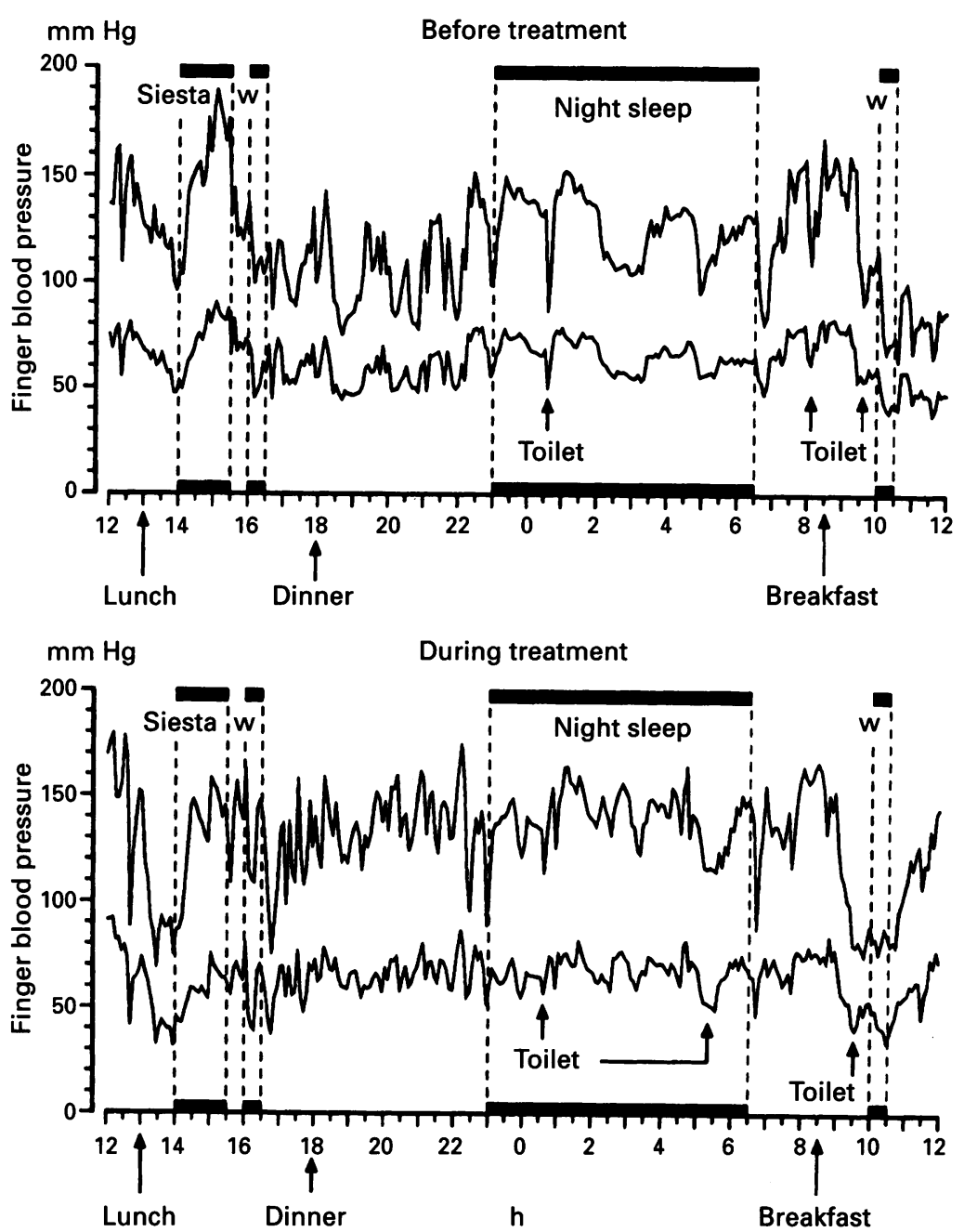

Figure 124 hystolic and diastolic blood pressure profiles in our patient before (upper panel) and during treatment (lower panel) with fludrocortisone, head-up tilt sleep, and salt loading. Data are shown as 5 min averages. Black bars indicate, from left hand to right hand side, siesta (1400-1530), walking (w) in the afternoon, night sleep (2300-0630) and walking in the morning (w). Arrows indicate the times of meals and visits to the toilet during the night and early morning. blood pressure and pulse pressure increased from 119 to $131 \mathrm{~mm} \mathrm{Hg}$ and from 56 to 67 $\mathrm{mm} \mathrm{Hg}$. Blood pressure in both instances did not show the drop usually seen during nocturnal sleep (fig 1). Blood pressures in the afternoon and in the evening were lower before than during treatment, but were similar in the early morning. However, the severity of postural symptoms before treatment forced the patient to spend most of the morning in bed and thereby masked low upright pressures. During treatment symptoms improved markedly and morning activities were less limited. The large fall in blood pressure induced by toilet visits was reduced during treatment. Lying supine awake in the early afternoon (siesta) caused a substantial blood pressure increase particularly before treatment.

Orthostatic tolerance improved over the day. Before treatment mean finger arterial pressure after 1-2 min standing was $33 \mathrm{~mm}$ $\mathrm{Hg}$ in the morning and $56 \mathrm{~mm} \mathrm{Hg}$ in the evening, the drops in blood pressure from values while supine control being $64 \%$ and $42 \%$, respectively. During treatment upright mean blood pressure measurements in the morning $(50 \mathrm{~mm} \mathrm{Hg}$ ) and in the evening (61 $\mathrm{mm} \mathrm{Hg}$ ) were higher and the drop in blood pressure was $47 \%$ and $35 \%$ from supine control. Before treatment the patient could stand without symptoms in the morning for only 1 minute, but during treatment she could stand for nearly $3 \mathrm{~min}$.

Before and during treatment she could not walk for long in the morning without becoming dizzy (fig 2). The tolerance to walking in the morning amounted to $8 \mathrm{~min}$ only, before treatment, compared with 15 minutes during treatment. Both before and during treatment blood pressure increased in the afternoon,
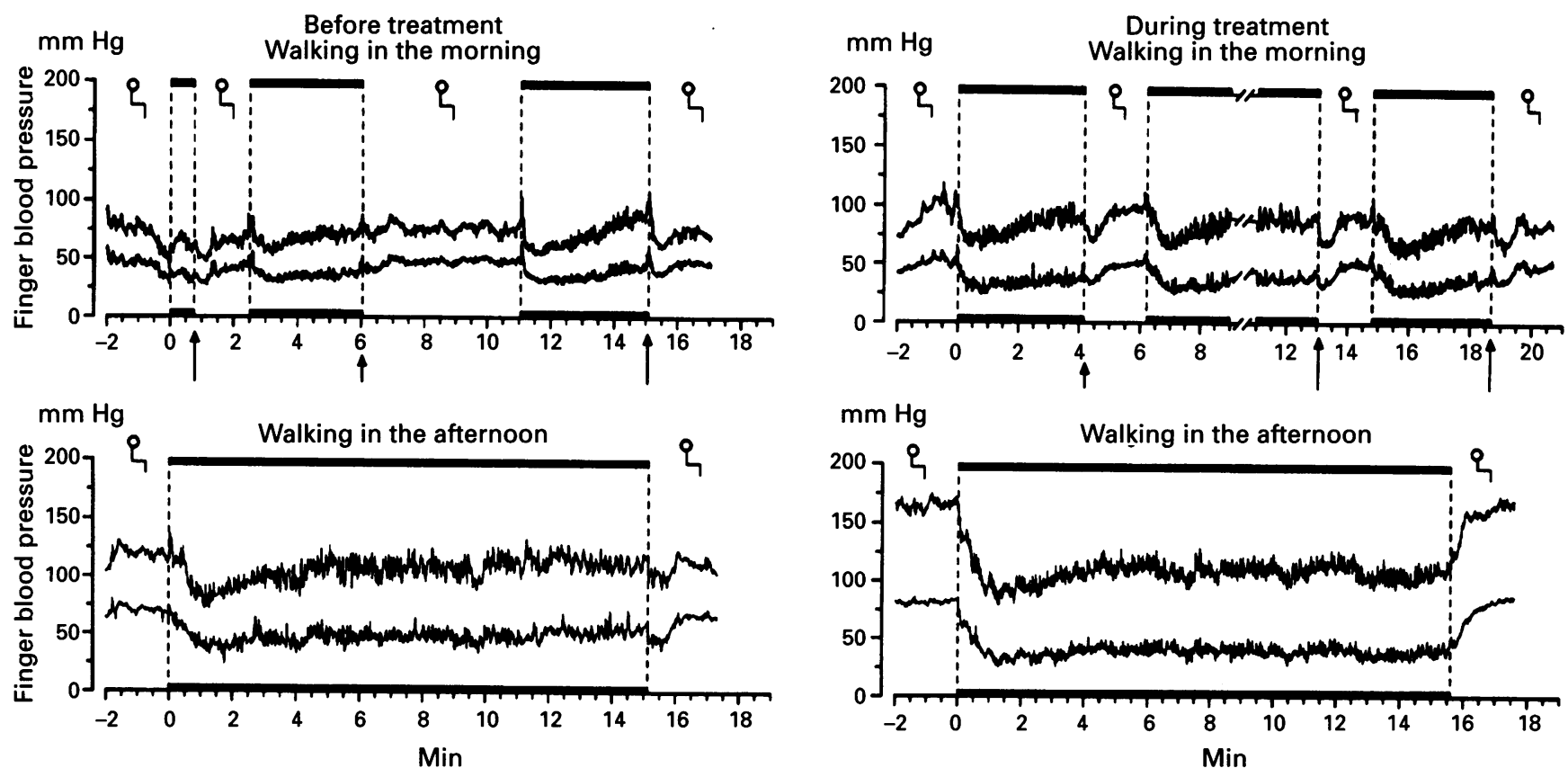

Figure 2 Walking in the morning (upper panels) and in the afternoon (lower panels), before (left panels) and during treatment (right panels). Walking periods are indicated by the black bars. Zero refers to the beginning of walking. Arrows mark the moment of dizziness and presyncopal symptoms that compelled the patient to sit down on a chair (recovery). Note the increase in sitting and walking blood pressure in the afternoon compared with the morning, both before and during treatment. 
and the patient could walk without major symptoms. The main effect of treatment was the increase of the level of morning and afternoon systolic blood pressure and pulse pressure during walking and sitting.

\section{Discussion}

In our patient continuous non-invasive blood pressure monitoring during the 24 hours by the Portapres device showed the real effect of treatment on orthostatic hypotension and the benefit on postural symptoms and patient's quality of life. It extended to everyday life the observations made by means of standardised laboratory tests-that is, that a relative small increase in mean blood pressure during treatment is sufficient to improve perfusion of the brain and to delay the occurrence of symptoms during various activities over the day.$^{67}$ The clinical information yielded by the Portapres recording showed how treatment affected blood pressure and symptoms during everyday life at home. In the past such information has come only from beat-to-beat intra-arterial recordings, ${ }^{8}$ which are too invasive for routine use. Non-invasive blood pressure measurements-such as, conventional sphygmomanometric measurements or intermittent blood pressure samples taken by automatic portable recorder-however, cannot be used to assess blood pressure variations throughout the day. ${ }^{9}$ Our data show that these problems can be overcome by the
Portapres device, which will be helpful to the clinical management of individuals with impaired autonomic control of circulation, especially when new treatments are evaluated. ${ }^{10}$

This study was supported by a grant from the Italian Society of Hypertension.

1 Mann S, Altman DG, Raftery EB, Bannister R. Circadian ariation of blood pressure in autonomic failure. Circulation 1983;68:477-83.

2 Zachariah PK, Krier J, Schwartz GL. Orthostatic hypotension and ambulatory blood pressure monitoring. f Hypertens 1991;9(suppl 8):S78-S80.

3 Wieling W, ten Harkel ADJ, van Lieshout J. Spectrum of orthostatic disorders: classification based on an analysis of the short-term circulatory response upon standing. Clin Sci 1991;81:241-8.

4 Imholz BPM, Langewouters GJ, van Montfrans GA, Parati G, van Goudoever J, et al. Feasibility of ambulatory, continuous 24-hour finger arterial pressure recording. Hypertension 1993;21:65-73.

5 Schmidt TFH, Wittenhaus J, Steinmetz TF, Piccolo P, Lupsen $\mathrm{H}$. Twenty-four-hour ambulatory noninvasive continuous finger pressure measurement with Portapres: a new tool in cardiovascular research. $f$ Cardiovasc Pharmacol 1992;19(suppl 6):S117-S145.

6 Ten Harkel ADJ, van Lieshout J, Wieling W. Treatment of orthostatic hypotension with sleeping in the head-up tilt position, alone and in combination with fludrocortisone. F Int Med 1992;232:139-45.

7 van Lieshout J, ten Harkel ADJ, Wieling W. Physical manoeuvres for combatting orthostatic dizziness in autonomic failure. Lancet 1992;339:897-8.

8 Bevan AT, Honour AJ, Stott FH. Direct arterial pressure recording in unrestricted man. Cli Sci 1969;36: recording

9 Di Rienzo M, Grassi G, Pedotti A, Mancia G. Continuous versus intermittent blood pressure measurement in estimating 24-hour average blood pressure. Hypertension 1983;5:264-9.

10 Hoeldtke RD, Streeten DHP. Treatment of orthostatic hypotension with erythropoietin. $N$ Engl f Med 1993; 323:611-5. 